\title{
"CLEAN STRATEGY" A COMMUNITY-BASED INTERVENTION AND ITS EFFECTS IN THE SMOKING PREVALENCE, CESSATION, AND TOBACCO-RELATED MORTALITY AND MORBIDITY IN THE MUNICIPALITY OF LIMASAWA, SOUTHERN LEYTE
}

\author{
Jessa Mae B. Rosete \\ Ministry of Health, Philippines
}

\begin{abstract}
The tobacco epidemic, one of the biggest public health threats, is the leading modifiable cause of non-communicable diseases in the Philippines. To protect the public from the ill effects of smoking, the local health board developed a "CLEAN Strategy" after the legislative committee signed the "Comprehensive Smoke-Free Ordinance in the Municipality of Limasawa" in 2016 which prohibits smoking and selling cigarettes in all public places and within 100 meters from these places. The main goal of this study was to complete a descriptive evaluation of the program implementation using the Theory-driven Evaluation grounded on HT Chen's Conceptual Framework of Program Theory. This study aims specifically at documenting the association of the CLEAN Strategy to the trend in the smoking prevalence, enrollment to the smoking cessation clinic, tobacco-related mortality and morbidity. A total of 381 smokers took part in this descriptive study and data were collected biannually using the Fagerstrom Test for Nicotine Dependence. Data were also collected from the Annual Mortality and Morbidity Report of the Municipality of Limasawa from 2016-2018. Analysis of trends revealed that the intervention resulted to a 16\% decrease in the prevalence of smokers from 2016 to 2017 and $30 \%$ decrease in 2018. Enrollment to the Smoking Cessation Clinic increased, with good follow up from the enrollees. Tobacco-related mortality and morbidity also significantly decreased from 2016-2018. It appears that the "CLEAN Strategy" of the municipality has lead to improved health outcomes through reduction of smoking prevalence, decrease in tobacco-related morbidity and mortality and increased enrollment in the smoking cessation clinic. The study suggests a community-based intervention that can be implemented to low-resource rural areas to achieve good health outcomes through the prevention of diseases caused by smoking.
\end{abstract}

Keywords: smoking, community-based, smoking prevalence, smoking cessation

\section{Introduction}

Smoking kills more than seven million people a year. According to the World Health Organization, smoking has caused six million deaths while second-hand smoke has caused the death of around 890,000 exposed nonsmokers. Indeed, this tobacco epidemic remains to be one of the biggest public health threats. What is alarming is that majority of the smokers live in low to middle income countries who suffer the burden of tobacco-related morbidity and premature mortality, leaving their families without any income and increasing out of pocket expenditures for health (WHO, 2015). Cigarette smoke has more than 4,000 chemicals with at least 250 harmful chemicals and 50 known to cause cancer. Despite this, the number of people smoking continues to increase with 1.1 billion tobacco users worldwide (WHO, 2015). In the Philippines, 16.5 million adults (23.8\%) reported current tobacco use in any form with the average age of initiation among daily smokers aged 15-34 is 17.5 years old and consuming 11 cigarettes per day on the average (GATS, 2015). Ten Filipino people die every hour because of smoking-related diseases. This translates to 240 deaths every day or 87,600 deaths every year. This alarming statistics has led to the ratification of the World Health Organization Framework Convention on Tobacco Control (WHO FCTC) in 2005, and since then the country has worked on MPOWER implementation for all six measures. MPOWER, a policy package intended to assist in the country-level implementation of 
effective interventions to reduce the demand for tobacco, is effective in reducing cigarette smoking among adults from 2007-2014 (Ngo, et.al, 2017)

To protect the public from the ill effects of smoking, the municipality of Limasawa, one of the areas in Southern Leyte has approved the ordinance known as the Comprehensive Smoke-free Ordinance of the Municipality of Limasawa, through the effort of the local chief executive and the sanggunian bayan, the legislative body. This ordinance was an ammendment to an Anti-Smoking ordinance signed in 2010. Important provisions of the ordinance include No smoking and selling of cigarettes to minors, No smoking and selling of cigarettes within $100 \mathrm{~m}$ of public places and conveyances, No designated smoking areas, No tobacco advertisments within $100 \mathrm{~m}$ of public places, and Prohibition of tobacco sponsorhips. A strategy called "CLEAN Strategy" was formulated to support the implementation of the ordinance.

Continued efforts to promote smoking cessation are essential for helping the nation meet the Sustainable Development Goal Number 13 which is to "reduce by one third premature mortality from non-communicable diseases through prevention and treatment" by 2030. Non-communicable diseases associated with smoking include stroke, aneurysm, cataract, heart and lung diseases and many types of cancer.

The extent to which tobacco control policies are correlated with smoking cessation was examined in 18 European countries and revealed that countries with more developed tobacco control policies have higher quit ratios than countries with less developed tobacco control policies (Schaap, et. al., 2008). Given the limited empirical evidence and the worldwide implementation of MPOWER policies, more research is needed to examine the effectiveness of the WHO FCTC. While an evidence-based, community-based smoking cessation intervention disseminated in partnership with community organizations was proven to be effective and feasible in a state in USA, no research has been done to describe the community based strategies in the Philippines and how it affected the population (Asvat, et al. 2014). The municipality of Limasawa has created a communitybased program against smoking called the "CLEAN Strategy", which was established for three years since 2016. This pioneer program was structured based on the MPOWER guidelines which gives the researcher an opportunity for outcome evaluation. The study seeks to address the burden in middle to low income countries by recommending community-based, low-cost and sustainable strategies to combat smoking and its ill effects. It also seeks to utilize the community resources and manpower to facilitate the strategies to ensure sustainability. As smoking in area of the study continues to become one of the greatest threat to the public, this study seeks to improve the local health situation by decreasing those affected by the dangers of smoking.

The goal of the study is to complete a descriptive evaluation of the program implementation using the Theorydriven Evaluation grounded on HT Chen's Conceptual Framework of Program Theory. This study aims specifically at documenting the association of the CLEAN Strategy to the trend in the smoking prevalence, enrollment to the smoking cessation clinic, tobacco-related mortality and morbidity.

\section{Analytical Framework}

HT Chen's Conceptual Framework of Program Theory (Figure 1) is often used to assess community interventions (CLS Coryn, et. al., 2011). This theory-driven model utilizes mixed methods and derive data from multiple sources. Theory-driven evaluation uses the action model and change model to address contextual factors and planning and implementation issues that are greatly interested to stakeholders. The action model is a systematic plan for arranging staff, resources, settings, and support organizations to reach a target group and deliver intervention services. The action model consists of the following elements: implementing organization, program implementers, peer org/community partners, intervention and service delivery protocol, ecological context and target population. A change model describes the causal process generated by the program. The elements of a change model consist of the following goals and outcomes, determinants, and intervention (Chen, 1990). 


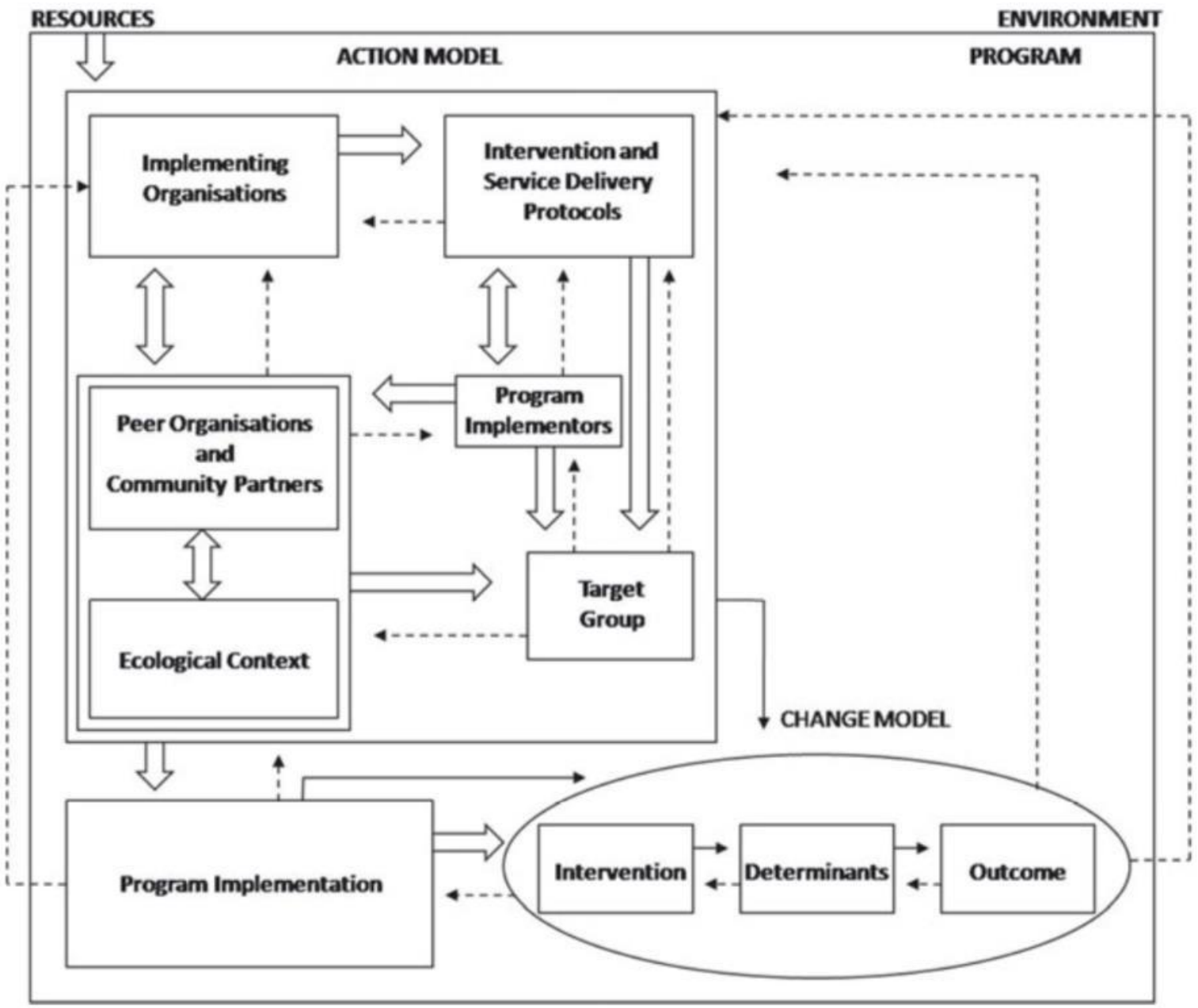

Figure 1:Conceptual Framework of Program Theory

\section{Methods}

A descriptive cross-sectional study was conducted in the municipality of Limasawa from the province of Southern Leyte. The researcher selected this municipality which has established the community-based program for three years since 2016. Limasawa is a small island municipality with a total population of 6,324 located in the southwestern tip of Southern Leyte province. The municipality consists of six barangays, the smallest administrative unit under the municipality, similar to a village in other countries. This study was conducted in all six barangays called Cabulihan, Triana, San Agustin, San Bernardo, Magallanes and Lugsongan.

The public health system in the area includes one Rural Health Unit (RHU), 3 Barangay Health Stations (BHS), manned by one Doctor, 1 Public Health Nurse, 3 Midwives and 10 deployed human health resources by the Department of Health. The RHU is the only healthcare facility which is limited to providing primary care to the whole municipality, BHS provide prenatal care, health education and public health services. The municipality has a functional Expanded Local Health Board, headed by the municipal mayor that conducts monthly meetings to discuss issues, execute and compose legislations specifically for the health of the community.

Sources of data include manuscripts and files of the implementation of the Anti-smoking program in the municipality, collated by year from 2016 to 2018. A smoking status survey was conducted to all residents through house-to-house visitation at the baseline year (2016). The survey only included current smoking status. At baseline, there was a total of 381 smokers identified. The 381 smokers were followed up every 6 months using the Fagerstrom Test for Nicotine Dependence. This test assesses a smoker's level of dependency on 
nicotine and has established validity and reliability in previous research. The total scores range from 0 to 10 with higher scores suggesting more nicotine dependence. Nicotine dependence was classified into three levels based on these composite scores: low (0-3), medium (4-6), and high (7-10). Smoking prevalence was measured as the percentage of current smokers among the total population.

Smoking cessation program in the study is a voluntary enrollment of the current smokers where brief tobacco intervention is done and completed after four once-a-week sessions. Enrollment, drop out rate and completion rate were compared from 2016-2018. Mortality and morbidity reports were derived from the Annual Statistical report of the Field Health Service Information system (FHSIS) of the municipality submitted by the health unit from 2016 to 2018 .

\section{MPOWER}

Ratified by the WHO FCTC, MPOWER is a package of six highly effective and cost-effective measures meant to assist all countries in implementing a tobacco control strategy: (M) monitoring tobacco use and prevention policies, $(\mathrm{P})$ protecting people from tobacco smoke, $(\mathrm{O})$ offering help to quit tobacco use, $(\mathrm{W})$ warning about the dangers of tobacco, (E) enforcing bans on tobacco advertising, promotion and sponsorship, and (R) raising taxes on tobacco (WHO, 2015). These measures encompass a comprehensive set of policies that have been shown to reduce smoking and provide guidelines for countries where more actions are needed.

\section{CLEAN Strategy}

The CLEAN Strategy of the municipality of Limasawa is an innovative strategy by the Municipal Local Health Board to address tobacco-related mortality and morbidity in the municipality. It was initiated after the Municipal Ordinance 2016-06, called "Comprehensive Anti-Smoking was approved by the municipal legislative office in 2016. The strategy aims to increase knowledge of the community regarding the harmful effects of tobacco smoke, to decrease current tobacco use, to decrease tobacco-related mortality and morbidity. The strategy is a comprehensive, integrated, community-based program which is anchored on the MPOWER strategies. CLEAN is an abbreviation for Collaboration, Legislation, Enforcement, Advocacy, and Networking.

\section{Collaboration}

A smoking task force constituted by different sectors, with different functions as stated in the municipal ordinance was formed immediately after it was signed in 2016. The concept of collaboration in this strategy is that all sectors work hand in hand to achieve the goal of a smoke free community. These sectors including the Department of Education, Agriculture, Health, Religious sector and the Non-government sector, are all involved in planning, and they comprise the Smoke-free task force of Limasawa. This inter-sectoral collaboration meets regularly to formulate action plans and strategies to better implement the ordinance.

\section{Legislation}

To strengthen its implementation, additional executive orders were made such as deputizing volunteers to enforce named "bantayBAGA". All business establishments getting business permit are mandated to place "No smoking" and graphic health warning signs in their premises and the government departments are encouraged to utilize smoke-free venues. An executive order was also released prioritizing the employment of nonsmokers for regular and job order positions in all local government offices. The strategies of legislation were targeted to provide more implementing rules and regulations to engage the community and influence them not to smoke. Part of legislating is providing funds thereof for the implementation. In 2016, an amount of 30,000 pesos was allocated as Anti-Smoking Budget, appropriated from the General Fund for its first year; increasing by 20,000 pesos on the consecutive year. Additional executive orders were made, representatives from each barangay were deputized to enforce specific provisions of the ordinance such as the issuance of citation tickets, and all business 
establishments were required to place Graphic Health Warning signs upon application of their business permit. The local chief executive also issued an order to prioritize the employent of nonsmokers for regular and job order positions in all Local Governement Offices.

\section{Enforcement}

The Philippine National Police of Limasawa is the agency in charge of the enforcement of law, prevention and control of crimes, maintaining peace and order and ensuring public safety. As enforcement is considered the backbone of this strategy, specifically in the CLEAN strategy, they supervise in the enforcement of the Comprehensive Smokefree Ordinance of Limasawa and submit monthly reports on the violators and corresponding actions taken based on the provision of the law. Enforcers training was done yearly to reinculcate and reorient the PNP and deputized enforcers, with feedback and active discussion on its enforcement. The process of enforcement is strengthened by the presence of an AntiSmoking hotline "Bantay BAGA", a mobile number owned by the PNP where reporting violators can be easily done by a layman. This hotline number is posted in all No Smoking Signs and Graphic Warning signs posted in all strategic places. The task force also deputized "common people" or citizens, and through the PNP, trained these people on how to enforce. They were dispersed in different areas to serve as eyes in the enforcement.

The process of apprehending violators starts with issuance of citation ticket by the police officer after an evidence is confirmed. This citation ticket should be payed at the Treasurer's Office within 3 days, otherwise they will be called in court. At the start of 2018, Barangay SmokeFree task force were organized in each barangay which served as clusters of enforcers in each barangay.

\section{Advocacy}

The municipality used the hashtag Smoke-free Limasawa "\#smokefreeLimasawa" for its municipal wide campaigns. In a collaborative effort, signages and graphic health warning signs were put up in strategic locations such as the school, government buildings, covered courts and waiting areas. Since tobacco advertising and promotion are believed to motivate adolescent experimentation and maintenance of tobacco use through shaping positive attitudes and beliefs about smoking (Lovato, et.al., 2003), all small stores were posted with these signs. Being a tourist destination, all tourist spots have the signages with the participation of the private owners. The inter-island vessels which are the main mode of transportation to the island were also given large tarpaulin with A no smoking sign. Tobacco advertisment which were no longer allowed were replaced by No smoking signages given by the local health office in the first year. Educating the community regarding the ill effects of smoking became a vital aspect, and advocacy campaigns included health lectures integrated in all health programs. World NO Tobacco Day was celebrated yearly, with motorcade as vehicle of information, parade and awarding of smoking ambassadors. In 2017, the campaign was extended to the youth, as teachers incorporate antismoking lectures in their teaching plans. The Sanggunian Kabataan, the youth organization in the community, initiated a poster making contest for the secondary students with the theme on Anti Smoking.

A smoking cessation clinic was opened in the municipal health office which is manned by the doctor and a trained midwife, and is strategically located at the back building to give privacy to the patients. Capacity building was done to the health staff to be able to assist in the management of the smoking cessation clinic. A Brief Tobacco Intervention Skills training was conducted to the health staff and the barangay health workers. Strengthening of the smoking cessation clinic is based on the multi-theory model of health behavior change which dissects health behavior change into two components: the initiation of behavior change which entails the decision to quit smoking and sustenance or continuation of the health behavior change which entails attaining abstinence (Sharma, et.al, 2017). This strengthens the first construct of the initiation in the theory which emphasizes the two-way communication between the person facilitating smoking cessation (counselor, physician, etc) and the person wanting to quit. In the Smoking Cessation Clinic, the advantages of quitting over 
the disadvantages were highlighted in counseling and the patient is given a brochure afterwards. A smoking quitline was established in 2017, a mobile number held by the trained midwife to handle calls and inquiries regarding smoking cessation. Patient consultation forms included smoking status as the 5th vital sign.

\section{Networking}

The strategy is improving our local service delivery network. Referral system for the smoking cessation clinic was established from the BHS to the RHU. In addition, networking means communication with other towns to strengthen our advocacy or ripple its effects.

Networking was utilized to influence other municipalities to achieve a smoke-free environment, by providing them with technical assistance. Networking strategy also involved gaining funds from non-government organizations and groups outside the town. With limited funds to implement this strategy, private groups and individuals assisted by giving sponsorships or in kind materials like tarpaulin, brochures. Networking this strategy also involved influencing other communities and municipalities to start with their smokefree campaign.

\section{Results}

The analysis of results from the study are shown in the subsequent table and figures. Table 1 shows the strategies in the community based anti-smoking program clustered biannually based on the date of its implementation. Most of the strategies were done in January 2017 with advocacy being strategically done throughout the years. Legislation were augmented at the start of January 2017, while collaboration was started as early as July of the first year of the implementation.

Table 1 Timeline of CLEAN Strategy

\begin{tabular}{|c|c|c|c|c|}
\hline $\begin{array}{l}\text { January to June } \\
2016\end{array}$ & July to December 2016 & $\begin{array}{l}\text { January to June } \\
2017\end{array}$ & $\begin{array}{l}\text { July to December } \\
2017\end{array}$ & $\begin{array}{l}\text { January to June } \\
2018\end{array}$ \\
\hline $\begin{array}{l}\text { Enforcers Training } \\
\text { (Enforcement) } \\
\text { Launching and } \\
\text { Barangay Assembly } \\
\text { "Operasyon } \\
\text { Baklas" } \\
\text { Lectures on Ill- } \\
\text { effects } \\
\text { (Advocacy) }\end{array}$ & $\begin{array}{l}\text { Education and } \\
\text { Agriculture } \\
\text { Departments tapped } \\
\text { (Collaboration) } \\
\text { Training on Brief } \\
\text { Tobacco Intervention } \\
\text { Skills (BTIS) } \\
\text { Opening of Smoking } \\
\text { Cessation Clinic } \\
\text { (Advocacy) } \\
\text { Technical Assistance } \\
\text { from a smoke-free } \\
\text { town } \\
\text { (Networking) }\end{array}$ & $\begin{array}{l}\text { Organization of } \\
\text { Bantay BAGA } \\
\text { (Enforcement) } \\
\text { Youth involvement } \\
\text { BHW training for } \\
\text { BTIS } \\
\text { (Advocacy) } \\
\text { Signature campaign } \\
\text { of department heads } \\
\text { (Networking) }\end{array}$ & $\begin{array}{l}\text { Prioritizing Non- } \\
\text { Smokers in } \\
\text { employment } \\
\text { EO: Patronizing } \\
\text { Smoke-free } \\
\text { Venues } \\
\text { (Legislation) }\end{array}$ & $\begin{array}{l}\text { Opening of } \\
\text { smoking cessation } \\
\text { clinic in the } \\
\text { barangay level } \\
\text { Smoke-free } \\
\text { Barangay Contest } \\
\text { "Takbo Kontra } \\
\text { Tabako" Fun Run } \\
\text { (Advocacy) }\end{array}$ \\
\hline
\end{tabular}


Table 2 Smoking prevalence and Nicotine Dependence from 2016 to 2018.

\begin{tabular}{lllllll}
\hline & $\begin{array}{l}\text { Baseline } \\
(2016)\end{array}$ & $\begin{array}{l}\text { After 6 } \\
\text { months }\end{array}$ & 2017 & $\begin{array}{l}\text { After 6 } \\
\text { months }\end{array}$ & 2018 & $\begin{array}{l}\text { After 6 } \\
\text { months }\end{array}$ \\
\hline Smoking Prevalence & $6 \%$ & $5.7 \%$ & $5.0 \%$ & $4.7 \%$ & $4.1 \%$ & $3.5 \%$ \\
\hline Nicotine Dependence & 4.93 & 4.94 & 4.59 & 4.43 & 4.04 & $3.93(2.74)$ \\
Mean (SD) & $(3.50)$ & $(2.83)$ & $(2.88)$ & $(2.96)$ & $(2.87)$ & \\
\hline Low & $33.86 \%$ & $35.75 \%$ & $35.31 \%$ & $39.60 \%$ & $43.97 \%$ & $47.32 \%$ \\
\hline Moderate & $33.07 \%$ & $31.28 \%$ & $34.69 \%$ & $32.21 \%$ & $32.68 \%$ & $31.25 \%$ \\
\hline High & $33.07 \%$ & $32.96 \%$ & $30.00 \%$ & $28.19 \%$ & $23.35 \%$ & $21.43 \%$ \\
\hline
\end{tabular}

At baseline, using the Fagerstrom, mean nicotine dependency scores for all participants indicated moderate levels of dependency $(\mathrm{M}=4.93, \mathrm{SD}=3.5)$. The mean dependency scores shown in table 2 has reached low levels $(M=3.93, S D=2.74)$ in 2018 when strategies done were focused on Legislation, Enforcement and Advocacy. There is an equal distribution of the levels of nicotine dependence at baseline. In table 2, a marked discrepancy among dependency levels is noted as the CLEAN strategy has been implemented. Those who scored in the low nicotine dependence from (33.86\%) at baseline has increased to almost 50\% (47.32\%) after 3 years of implementation. Those who scored at moderate nicotine dependence remained constant at $31-33 \%$ (1/3 of all responders). The largest drop in the high nicotine dependence range happened in midyear of 2017 to 2018 after the strategies were done such as Prioritizing Non-Smokers in employment. Patronizing Smoke-free Venues, Advocacy on the youth through poster making for Students and networking with other towns to be smoke free. This outcome is consistent with previous study on the impact of smoking control policies on smoking trends. If MPOWER had been implemented globally starting in 2010 with a $100 \%$ price increase for cigarettes, the authors estimate that global cigarette smoking prevalence would be $15.4 \%$ in 2020 and $13.2 \%$ in 2030 (Mendez, 2013).

There was a consistent downward trend in the prevalence of current smokers in the whole municipality over the three year study period (Table 2). Baseline prevalence at $6 \%$ fell to almost fifty percent at the end of three years. The rate of decline between 2016 to 2018 was 1 to $1.5 \%$ per year. A study of Ngo, et.al., revealed that an increase in composite score in MPOWER reduces smoking prevalence by 0.2 percentage points among adults. MPOWER policies were effective in reducing cigarette smoking among adults (Ngo, et.al., 2017)

Table 3 Smoking cessation clinic data from 2016 to 2018

\begin{tabular}{llll}
\hline & 2016 & 2017 & 2018 \\
\hline Total of Persons Enrolled & 25 & 75 & 83 \\
\hline Drop out rate & 0 & 0 & 0 \\
\hline Number of Quitters & 23 & 60 & 74 \\
\hline Number of Relapse & 2 & 15 & 9 \\
\hline
\end{tabular}

Enrollment to the smoking cessation program also increased with zero drop out rate. In congruence with the decrease in prevalence, there is an increasing number of quitters and decreasing number of relapsing patients in the smoking cessation program. In table 2, there are two who relapsed in 2016, a total of twenty-one successful quitters, and relapse rate is eight percent (8\%). In 2017, there is a total number of successful quitters at sixty out of seventy-five of those enrolled and a relapse rate of twenty percent (20\%) and in 2018, there are more enrollees at eighty-three with a decrease in relapse rate at ten percent $(10 \%)$. 
Table 4 Tobacco Related-Mortality from 2016 to 2018

\begin{tabular}{llll}
\hline & 2016 & 2017 & 2018 \\
\hline Total mortality & 19 & 18 & 21 \\
\hline $\begin{array}{l}\text { Number of Tobacco related } \\
\text { mortality }\end{array}$ & 16 & 16 & 18 \\
\hline Percentage & $84 \%$ & $89 \%$ & $80 \%$ \\
\hline
\end{tabular}

All tobacco related morbidities in the community were gathered from the list of the top ten causes of morbidity derived from the FHSIS. In Figure 2, among the top ten which are tobacco-related are upper respiratory tract infection (URTI), pneumonia and bronchial asthma. There is a definite decline among cases throughout the years with the greatest decline from 2016-2017 and 2017-2018 for URTI at nineteen percent (19\%), and twentyone percent $(21 \%)$ respectively. Pneumonia decreased from 2016-2017 and 2017-2018 at six point five percent $(6.5 \%)$ and thirty percent $(30 \%)$ respectively while bronchial asthma decreased to nineteen (19\%) and twentysix percent $(26 \%)$ respectively.

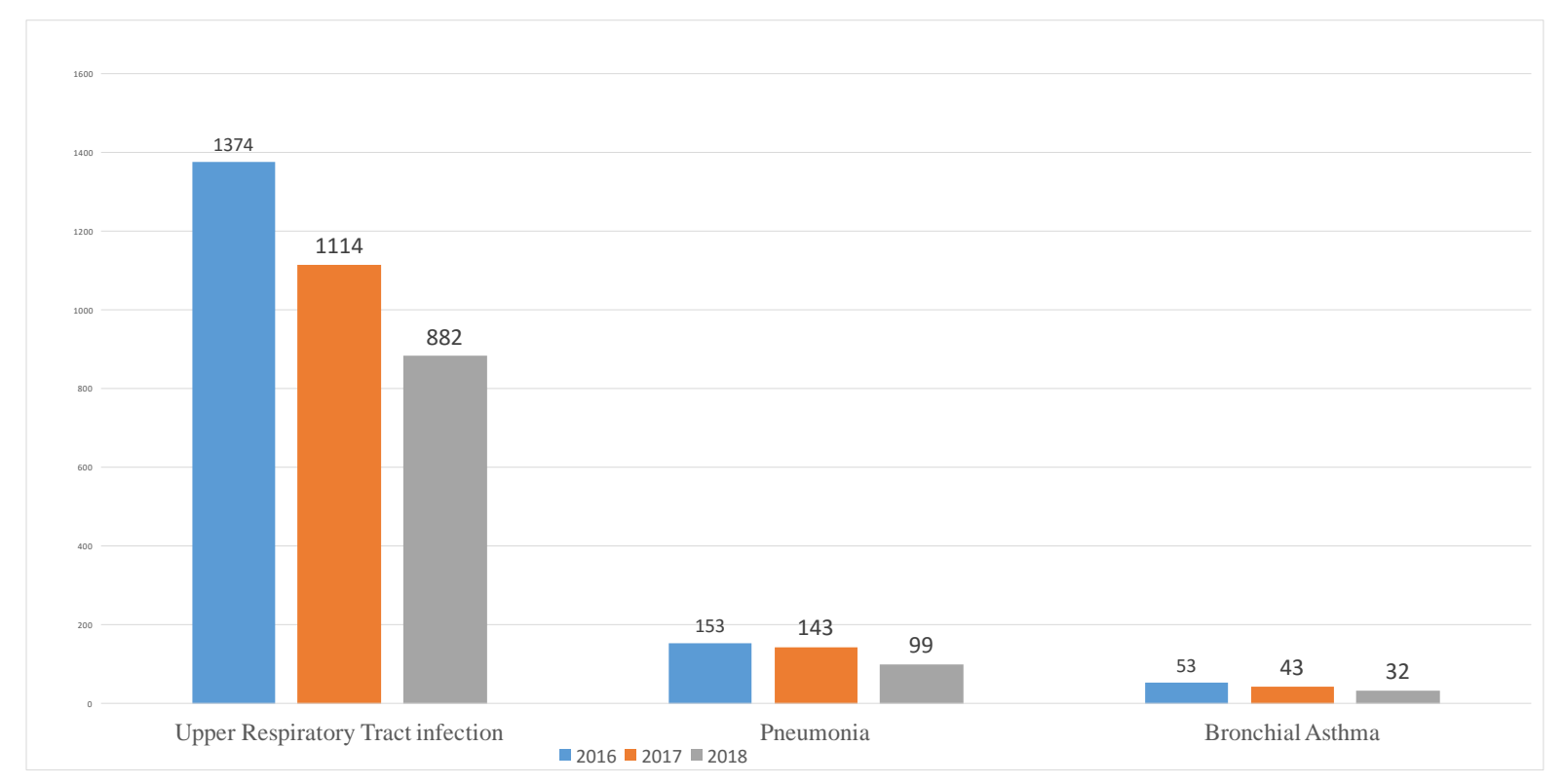

Figure 2 :Tobacco-related Mortality from 2016 to 2018

From the list of the top ten causes of mortality in the community, tobacco-related causes were isolated and the results as shown in Table 4 revealed that from 2016 to 2017 there is an increase from eight-four percent (84\%) to eighty-nine percent (89\%) while it decreased in 2018 to eighty percent $(80 \%)$ of the total causes of mortality. This is consistent with a previous study done by Anthonisen et.al. (2005), which showed significantly lower allcause mortality in the intervention group than in the control group (8.83 per 1000 person-years vs. 10.38 per 1000 person-years; $\mathrm{P}=0.03$ ) after a smoking cessation intervention program.

\section{Integrating the results in the analytical framework}

Figure 3 shows the integration of HT Chen's Conceptual Framework of Program Theory of the results of the implementation of the study. In the action model, the local government of Limasawa has created the CLEAN Strategy, in collaboration with all sectors and departments to create an Anti-smoking task force targetted to both smokers and non-smokers in the community. The CLEAN Strategy implemented in 2016 has led to outcomes such as a decrease in smoking prevalence, decrease in tobacco-related mortality and morbidity and increased voluntary enrollment in the smoking cessation clinic. Althought the determinants of the change model has not 
been thoroughly examined, there are these identified throughout the strategy: increased knowledge due to the advocacies and compliance to law due to legislation and enforcement.

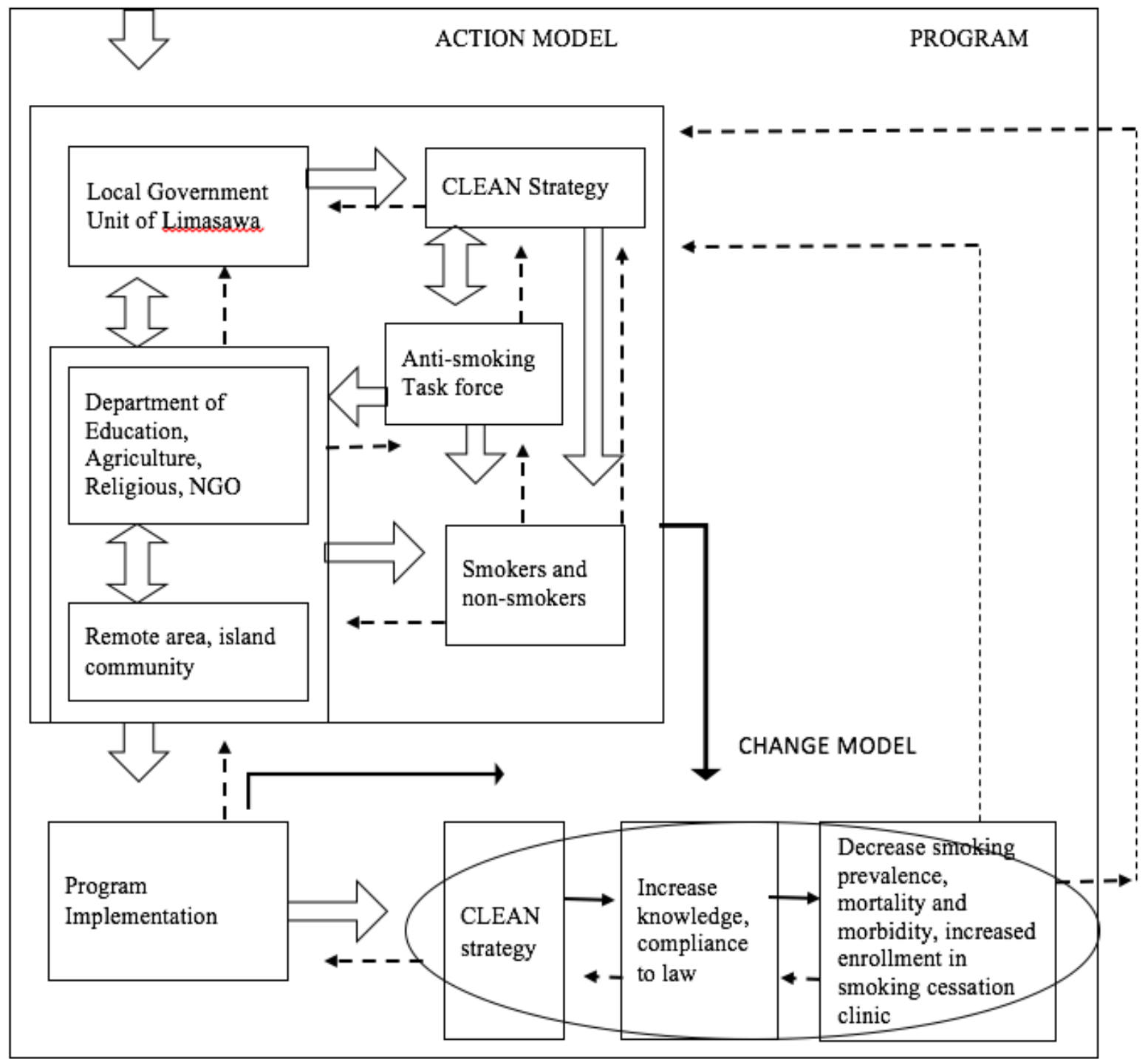

Figure 2: Integrating study results into HT Chen's Conceptual Framework of Program Theory

\section{Discussion}

There is a lack of existing researches showing an effective community-based anti-smoking program. Evaluation of the CLEAN Strategy developed by the municipality of Limasawa provides the evidence base for combatting smoking and its ill effects to the community. The purpose of this paper was to address the gap in the literature on anti-smoking programs by reporting on the outcomes associated with a community-based intervention. The results of this study are limited by a descriptive design. While the descriptive nature of results provides insights to the extent and possible influence of the CLEAN strategy, inferences regarding the direct impact of these activities on tobacco-related mortality and morbidity cannot be determined. Data was only collected from the annual statistical report on mortality and morbidity, and individual cases were not investigated for the smoking status or exposure. Further research, particularly retrospective cohort study is needed. 
By linking the CLEAN Strategy with the community smoking prevalence and enrollement to the smoking cessation clinic, this study provides evidence that strengthening legislation against smoking and advocating on a smoke free environment through inter-agency collaboration should go together for better outcomes. In a study on the challenges and opportunities of a tobacco policy in Australia, it is recommended that the whole of community approaches must be used to improve collaborative efforts between service providers, as the lack of collaboration between organizations is a barrier in the implementation of anti-smoking programs (2012). The direct link between the anti-smoking task force, the different departments and non-government institutions (NGO) and the Local Government of Limasawa as seen in Figure 2 shows the collaborative approach to the successful implementation of the program, making them a vital aspect in producing change in outcomes. This finding is consistent with prior research, yet unique to the context of the municipality, and suggests that community-based smoking programs are powerful cost effective strategies influencing smoking prevalence, mortality and morbidity. Furthermore, intense police enforcement is essential to overcome the documented effect of fear in discouraging smokers from purchasing cigarettes (Lantz, et.al, 2000)

Several studies suggest that smoking policies are associated with decreased amounts of smoking (Lewit, et.al., 1981; Pentz, et al., 1989). In this study, aside from prohibiting smoking in all public places, total ban of selling tobacco and enforcing all business establishments to have graphic health warning signs have created good intermediate outcomes. These policies have discouraged people to purchase cigarettes, leading to a decrease in their consumption. Prioritizing Non-smokers in employment and prioritizing smoke-free venues for public gatherings also created impact. This is consistent with a study concluding that workplace smoking bans were associated with reduced rates of smoking, particulary among heavy smokers with reduction in consumption as much as 25 percent (Borland, et.al., 1990).

In the study, one of the most important strategy was enforcement. The active involvement of the law enforcing body, the Philippine National Police (PNP), who is a member of the smoking task force is linked to the outcome of decreasing prevalence of smoking. The PNP is incharge of apprehending violators, conducting barangay patrol, issuing of citation tickets and arresting violators as needed. A study by Jason, et.al. revealed that in communities with regular enforcement rates of regular smoking were $8.1 \%$ compared to $15.5 \%$ in communities without regular enforcement. The study also concluded that adolescents who had restricted access to tobacco products were less likely to become regular smokers (1999).

\section{Conclusion}

The findings of this study highlight the positive effect of the CLEAN Strategy to the trend in the smoking prevalence, enrollment to the smoking cessation clinic, tobacco-related mortality and morbidity and through the Conceptual Framework of Program Theory, the model of how the implementation created outcomes was shown.

A research program should address the limitations of the study by (1) improving the internal validity of the intervention which include randomization and inclusion of a control group; (2) incorporating smoking cessation clinic practices such as verification of smoking status through nicotine level tests, nicotine replacement therapy, and long-term follow-up; (3) inclusion of determinants for the outcome and identifying factors affecting the implementation, the factors associated with smoking cessation, compliance and quitting; comparing between different populations and groups.

After the community-based intervention, despite the lack of correlational statistics due to unavailability of a control sample, the strength of this study is that there is shown improvement from the baseline for the three-year study period especially in the smoking prevalence and cessation. The outcomes in this study can be compared to outcomes in other municipalities or international standards in future studies.

Existing studies have focused on smoking interventions solely on policy making, and knowledge improvement in the youth. It is believed that this is the first Filipino study to focus on the implementation of a comprehensive 
community-based anti-smoking program in a rural-remote area. The researcher would like to recommend that an extensive implementation of Anti-smoking policy be done particularly on the aspect of banning tobacco smoking in all public places and tobacco selling within $100 \mathrm{~m}$ of public places. Furthermore, since three years are not adequate to fully measure the effect of programs on the mortality and morbidity, a study can be done by monitoring the community for 10-15 years to assess the long term impact of the program on prevalence, mortality and morbidity. A larger population is recommended and longer follow up is needed to quantify effects.

Despite of the limitations, the strength of this research is in highlighting the strategies in the implementation of a smoke-free community. It was noted that the enrollment to the smoking cessation clinic increased after the implementation of the CLEAN Strategy. This suggests that strengthening the advocacy contributed to the health behavior change: deciding to quit smoking and abstinence. Education and adequate counseling must be done to encourage adequate follow up and guidance. Future research should consider investigating on the factors that affect smoking cessation.

In summary, understanding the strategies employed when implementing such programs can assist rural-remote primary health care services to design and deliver more effective anti-smoking programs. The present findings have the potential to improve the effectiveness and cost-benefit of anti-smoking programs, thereby improving health outcomes in the community setting.

\section{References}

Anthonisen, Nicholas R., et al., 2005. "The effects of a smoking cessation intervention on 14.5-year mortality: a randomized clinical trial." Annals of internal medicine 142.4: 233-239.

Asvat, Y., Cao, D., Africk, J.J., Matthews, A. and King, A., 2014. Feasibility and effectiveness of a communitybased smoking cessation intervention in a racially diverse, urban smoker cohort. American journal of public health, 104(S4), pp.S620-S627.

Borland, R., Chapman, S., Owen, N., \& Hill, D. (1990). Effects of workplace smoking bans on cigarette consumption. American Journal of Public Health, 80(2), 178-180.

Chen, H.T., 1990. Theory-driven evaluations. Sage.

Coryn, C.L., Noakes, L.A., Westine, C.D. and Schröter, D.C., 2011. A systematic review of theory-driven evaluation practice from 1990 to 2009. American journal of Evaluation, 32(2), pp.199-226.

Jason, L. A., Berk, M., Schnopp-Wyatt, D. L., \& Talbot, B. (1999). Effects of enforcement of youth access laws on smoking prevalence. American journal of community psychology, 27(2), 143-160.

Lantz, P.M., Jacobson, P.D., Warner, K.E., Wasserman, J., Pollack, H.A., Berson, J. and Ahlstrom, A., 2000. Investing in youth tobacco control: a review of smoking prevention and control strategies. Tobacco control, 9(1), pp.47-63.

Lewit, E. M., Coate, D., \& Grossman, M. (1981). The effects of government regulation on teenage smoking. The Journal of Law and Economics, 24(3), 545-569.

Lovato, C., Linn, G., Stead, L.F. and Best, A., 2003. Impact of tobacco advertising and promotion on increasing adolescent smoking behaviours. Cochrane database of systematic reviews, (3).

Matthews, Alicia K., et al. "Results from a community-based smoking cessation treatment program for LGBT smokers." Journal of environmental and public health 2013 (2013).

Mendez D, Alshanqeety O, Warner KE. The potential impact of smoking control policies on future global smoking trends. Tob Control. 2013;22(1):46-51.

Ngo, A., Cheng, K.W., Chaloupka, F.J. and Shang, C., 2017. The effect of MPOWER scores on cigarette smoking prevalence and consumption. Preventive medicine, 105, pp.S10-S14.

Pentz, M. A., Brannon, B. R., Charlin, V. L., Barrett, E. J., MacKinnon, D. P., \& Flay, B. R. (1989). The power of policy: the relationship of smoking policy to adolescent smoking. American Journal of Public Health, 79(7), 857-862.

Philippines, G.A.T.S., 2011. Philippines Global Adult Tobacco Survey Country Report 2010. 
Robertson, Jan A., et al. "Translation of tobacco policy into practice in disadvantaged and marginalized subpopulations: a study of challenges and opportunities in remote Australian Indigenous communities." Health research policy and systems10.1 (2012): 23.

Schaap, M.M., Kunst, A.E., Leinsalu, M., Regidor, E., Ekholm, O., Dzurova, D., Helmert, U., Klumbiene, J., Santana, P. and Mackenbach, J.P., 2008. Effect of nation-wide tobacco control policies on smoking cessation in high and low educated groups in 18 European countries. Tobacco control, pp.tc-2007.

Sharma, M., Khubchandani, J. and Nahar, V.K., 2017. Applying a new theory to smoking cessation: case of multi-theory model (MTM) for health behavior change. Health promotion perspectives, 7(2), p.102.

WHO, Global Health Observatory Data, Date of access: 12/31/2018 https://www.who.int/gho/tobacco/use/en/

WHO. MPOWER: Six Policies to reverse the tobacco epidemic. World Health Organization; 2008. 